\title{
School Fatigue and Free Time Activities in a Group of Adolescents from Two Information Technology High Schools
}

\author{
Adriana Albu, Florin Dima*, Sabina Dorofte, Irina Abdulan \\ "Grigore T. Popa" University of Medicine and Pharmacy, Iasi, Romania
}

How to cite this paper: Albu, A., Dima, F. Dorofte, S. \& Abdulan, I. (2017). School Fatigue and Free Time Activities in a Group of Adolescents from Two Information Technology High Schools. The Educational Review, USA, 1(3), 47-53. http://dx.doi.org/10.26855/er.2017.03.001

*Corresponding author: Florin Dima, "Grigore T. Popa" University of Medicine and Pharmacy, Iasi, Romania.

\begin{abstract}
Fatigue is a physiological phenomenon that disappears through rest. The study of school fatigue is very important because the physical and intellectual effort of students is limited. The study was carried out on a group of 184 high school students from two Moldavian counties, in Romania. A questionnaire was applied with questions about the presence of fatigue, methods of spending free time and social relationships. Fatigue is rarely present in half of the students questioned. In $57.06 \%$ of cases, they find themselves tired in the morning. The time spent watching television (TV) is between $0.5-1$ hour a day (41.84\% of cases), and computer use is between $2-3$ hours a day (46.19\%). There are young people who have no friends and who do not spend their free time with them. Free time spent in front of the TV or computer is a source of fatigue and not rest.
\end{abstract}

\section{Keywords}

Fatigue, Leisure, Friends

\section{Introduction}

Fatigue is a physiological phenomenon that occurs when the body's normal physical or intellectual effort capacity is exceeded. It disappears through active rest (recreational activities) during the day and through passive rest (sleep) during the night.

The study of fatigue during school activity is essential for maintaining the health of children and young people. Their body is stressed by growth and development processes, so too much physical and intellectual effort can lead to the disruption of the two processes specific to childhood and adolescence. On the other hand, schooling is essential in this stage of development and evolution towards adulthood (Eftodi, Mesina \& Ferdohleb, 2013).

School rigors must exist, but they will be tailored to the young person's age, gender, and effort capacity. Any inadequacy becomes risky, as it can lead to chronic fatigue associated with lower school performance, school failure and even school abandonment (Cosmovici \& Iacob, 2008). It is a situation that needs to be carefully studied under the current conditions, in which many young people still fail to obtain passing grades for the baccalaureate examination, even though they have attended high school and have had good school results.

Another aspect that needs to be closely monitored is how young people choose to spend their leisure time. Currently, the trend is to spend free time in front of the television or computer screen, which favors the exacerbation of fatigue and the appearance of isolation. We must take into account the possibility of computer addiction syndrome, a recent phenomenon that is considered as serious as drug addiction. There is no question of completely renouncing television or computer use but it is a matter of 
carefully monitoring the time spent on such devices, so that it does not become a risk factor for triggering pathological fatigue.

\section{Objectives}

Knowledge of the frequency of fatigue in questioned students; the appreciation of the differences that appear/do not appear between the two groups studied, taking into account the fact that the high school profiles are similar; evaluating the time spent by pupils on leisure activities represented by watching TV programs and computer use; the appreciation of social relations based on the number of real friends and the time spent outside the house, with them.

\section{Material and Methods}

The study was conducted on a group of 184 pupils from the 10th and 12th grades of two computer science high schools in two counties of Moldavia, and namely, the Computer Science High School from Piatra Neamt where 96 students were questioned and the Computer Science High School from Iasi where 88 students were questioned. These students completed a questionnaire with questions about the presence of school tiredness, how to spend free time and the presence of friends. It is a questionnaire which contains 3 questions about the presence of the phenomenon of school fatigue:

Do you feel tired?: often; rarely; never.

How do you feel in the morning?: rested; tired; very tired.

During the week when do you feel tired?: at the start; in the middle; at the end.

The questionnaire also contains four questions about how students spend free time and the presence of friends:

How many hours per day do you spend watching television (TV)?: none; 0.5-1 hours; 2-3 hours; 4-5 hours.

How many hours per day do you spend on the computer?: none; 0.5-1 hours; 2-3 hours; 4-5 hours.

How many close friends do you have?: none; one; two; three or more.

How many times per week do you go out on the town with friends?: never; 1 time; 2-3 times; 4-5 times; 6-7 times.

The questionnaire seeks to obtain information about the school and extra-curricular activities of young people. There is little knowledge concerning this topic, in our country, which makes the obtained information important. The results will be presented comparatively on the two studied groups. The results will be processed using the Pearson's chi-squared test.

\section{Results and Discussion}

The study will focus on two main directions: the assessment of the phenomenon of fatigue that occurs in students and how to spend leisure time. Leisure (active leisure) should lead to the removal of fatigue, but sometimes it exacerbates it.

To the question "Do you feel tired?" 42.39\% of answers were "often" which is an alarming number. A teenager who is frequently tired can easily get into the situation of exceeding normal effort capacity and triggering the phenomenon of pathological fatigue (Table 1).

Table 1. The presence of fatigue in students.

\begin{tabular}{cccc}
\hline \multirow{2}{*}{ Group } & \multicolumn{3}{c}{ Fatigue frequency } \\
\cline { 2 - 4 } & Often & Rarely & Never \\
\hline Neamt IT High School & 46 & 45 & 5 \\
Iasi IT High School & 32 & 48 & 8 \\
Total & 78 & 93 & 13 \\
$\%$ & 42.39 & 50.54 & 7.06 \\
\hline
\end{tabular}

Our attention is drawn to the $7.06 \%$ of young people who chose the "never" response, which is strange for a student. These 
young people either adapt very well to school rigors, or are less interested in school activities, so there is no fatigue. These responses occur in both groups, the calculated differences being statistically insignificant $\left(\mathrm{p}>0.05, f=2, \chi^{2}=2.968\right)$.

In another study conducted in Iasi on adolescents from three types of high schools (music, sports and general culture) the answer "rarely" was given in 50.21\% situations. The results obtained are practically the same as in the current study. In this study, differences between groups are statistically insignificant, a result somewhat expected because it is the same type of school (I.T. high school). In the study of three different types of high schools the differences obtained were statistically significant because the school demands were different for students from the music and sport high schools, which paid less attention to school education (Albu, Hodorca, Onose, Negrea \& Crăcană, 2016).

School demands tailored to young people's work capacity will create a level of fatigue that disappears after changing the type of activity and especially after a restful sleep. Under physiological conditions the student needs to wake up well rested in the morning. Such a response is only present in one-third of the students questioned. The rest of the students find they are tired in the morning (57.06\%) and even very tired $(9.23 \%)$ (Table 2).

Table 2. Fatigue in the morning.

\begin{tabular}{cccc}
\hline \multirow{2}{*}{ Group } & \multicolumn{3}{c}{ The presence of fatigue when waking up in the morning } \\
\cline { 2 - 4 } & Rested & Tired & Very tired \\
\hline Neamt IT High School & 26 & 57 & 13 \\
Iasi IT High School & 36 & 48 & 4 \\
Total & 62 & 105 & 17 \\
$\%$ & 33.69 & 57.06 & 9.23 \\
\hline
\end{tabular}

The presence of fatigue in the morning is a worrying element, as it suggests too much activity and an insufficient amount of sleep. The statistically insignificant differences $\left(p>0.05, f=2, \chi^{2}=5.704\right)$ are worrying because they tend to similar school demands that can easily be associated with the triggering of stress related reactions.

A similar result was obtained from students from another general high school in Iasi, where $53.42 \%$ of students were feeling tired in the morning. The study was conducted in 2010 and 2012 and highlights the increase in the frequency, of young people who wake up tired, from $46.57 \%$ in 2010 to $59.62 \%$ in 2012. At the same time we observe the decrease in frequency of those waking up well rested in the morning from $46.67 \%$ in 2010 to 32.29\% in 2012 (Albu A., 2013). It is a result that rai ses special issues related to the modest adaptation capacity of students to school rigors and the emergence of a growing phenomenon of fatigue.

Another aspect to be monitored is the time of week when students feel tired. Physiological fatigue occurs at the end of the work week after intense work. Rest during the weekend will allow the recovery of physical and intellectual work capacity (Table 3).

Physiological fatigue is present in only a quarter of the questioned students, the differences calculated being statistically insignificant ( $\mathrm{p}>0.05, f=2, \chi^{2}=3.589$ ). Our attention is drawn to the $37.50 \%$ of young people who feel tired at the beginning of the week after a weekend in which they spent hours in front of the television (TV) or computer screen.

Even though parents are at home at the end of the week, they do not interfere too often with the student's schedule, so it is more relaxed. Such a schedule should mean rest, time spent outside with friends and not exacerbating fatigue, as is often the case.

In the study conducted in Iasi on three different types of high schools, $18.98 \%$ of tired pupils appear at the end of the week, but the differences calculated are statistically significant. It draws attention to the general high school where the percentage of physically tired students (at the end of the week) is lower (Albu, Hodorca, Onose, Negrea \& Crăcană, 2016). 
Table 3. Fatigue during the week.

\begin{tabular}{cccc}
\hline \multirow{2}{*}{ Group } & \multicolumn{3}{c}{ The time of week when students feel tired } \\
\cline { 2 - 4 } & At the start & In the middle & At the end \\
\hline Neamt IT High School & 37 & 31 & 28 \\
Iasi IT High School & 32 & 39 & 17 \\
Total & 69 & 70 & 45 \\
$\%$ & 37.50 & 38.04 & 24.45 \\
\hline
\end{tabular}

In-depth studies are needed to know the causes of fatigue and to be able to intervene if necessary. Effective preventive action will allow students to monitor their health and avoid overload. The emergence of chronic fatigue can lead to school failure associated with one year repetition or school dropout, even in the case of an "elite" high school (Cosmovici \& Iacob, 2008; Clerget, 2012).

The results are worrying and require continued study of how to spend leisure and social relationships. The favorite way of spending leisure time is watching TV and computer games. These are sedentary activities, which can be associated with the risk of evolution towards increased body weight and the phenomenon of being overweight or even obese (Rada, 2017).

Watching television programs can be educational if they are adapted to the age group. Unfortunately, adolescents frequently follow adult programs that often incite violence. There are situations in which the TV is a constant presence in family life, being turned on in the morning and operating almost all day.

In the questioned students the answers are interesting because in one third of the cases they do not watch TV. The dominant viewing time is $0.5-1$ hour $(41.84 \%)$ which is considered appropriate (Table 4$)$.

Table 4. Time spent watching TV.

\begin{tabular}{cccc}
\hline Time spent watching TV & Neamt IT High School & Iasi IT High School & Total \\
\hline None & 25 & 43 & $68-36.95 \%$ \\
$0,5-1$ hour & 51 & 26 & $77-41.84 \%$ \\
$2-3$ hours & 18 & 18 & $36-19.56 \%$ \\
$4-5$ hours & 2 & 1 & $3-1.63 \%$ \\
\hline
\end{tabular}

Differences calculated are statistically significant for $\mathrm{p}<0.01\left(f=3, \chi^{2}=12.852\right)$ and draw attention to high school students in Iasi where the frequency of negative responses (none) is higher. TV programs may not fit the interests of the students, so they choose other ways to spend their free time.

In a study conducted in France, 55.8\% of 15-year-olds spend over 2 hours watching TV and 19.4\% of young people over 4 hours a day (Godeau, Arnaud \& Navarro, 2008).

The different result that is present in our study may also be due to the different quality of television programs. In our country television programs do not meet the demands of adolescents and especially those with high aspirations. International recommendations prescribe spending up to 2 hours per day on television or other information systems, a result that occurs in our study in most young people.

The habit of staying so much in front of the TV screen during adolescence often remains during adulthood. In a study of adults, it is noticed that at the age of $35-49,23.6 \%$ of people often watch television, while $40.85 \%$ use it for a short time or almost never (Rada, 2017).

Now, computer games are the most attractive way to spend free time. The situation is somewhat distinct for students in the studied group because they study at a computer science high school where computer programs are taught as a subject.

The computer and the internet can have positive effects on student development as it provides them with an abundance of information. On the other hand, the effects may be negative when accessing unnecessary programs or when time spent on the 
computer is too long (Alexander, 2010).

In most cases, young people spend 2-3 hours a day on the computer (46.19\%), which is quite a lot. One third of the students surveyed, sit at the computer 4-5 hours a day, which is a big problem. They stay in school for 6-7 hours and after that 4-5 hours on the computer, so we must ask ourselves if they have enough time to study, go outside with friends or sleep (Table 5).

Table 5. Time spent at the computer.

\begin{tabular}{cccc}
\hline Time spent at the computer & Neamt IT High School & Iasi IT High School & Total \\
\hline None & 3 & 6 & $9-4.89 \%$ \\
$0,5-1$ hour & 10 & 19 & $29-15.76 \%$ \\
2-3 hours & 49 & 36 & $85-46.19 \%$ \\
4-5 hours & 34 & 27 & $61-33.15 \%$ \\
\hline
\end{tabular}

Our attention is drawn to the $4.89 \%$ of negative responses that are strange for students at a computer science high school. Such responses are present in both groups, so the calculated differences are statistically insignificant ( $\mathrm{p}>0.05, f=3, \chi^{2}=6.236$ ).

Specialists recommend an acceptable time for spending in front of the computer is 1 hour, a response present in $15.47 \%$ of the students questioned.

In a study carried out on students from the Republic of Moldova, $10.3 \%$ of the responses were " 1 hour per day". Most of the responses are "2 hours" (16.6\%), "3 hours" (24.1\%) and even " $4-5$ hours" (14.6\%) per day (Croitoru, 2015).

The Internet can be effectively used in mass education programs for adolescent healthy living habits. Educational intervention should, however, be carried out by specialists in the field, in order not to provide young people with fragmented or even incorrect information (Coyne-Beasley, 2017).

On the other hand, internet and on-line communication can be a risk factor favoring the emergence of socio-emotional and behavioral problems. The teenager can feel alone, they may have problems communicating with real friends, becoming tempted to focus on the virtual ones. There is no question of renouncing internet use and online communication completely, but it is a matter of striking a balance between the on-line presence and communication with real friends (Buonomo, Cipriani, Piperno, Saddi \& Fiorilli, 2015).

The long time spent in front of the computer will be associated with the worsening phenomenon of fatigue but also with the risk of triggering computer addiction. Young people are always in front of the computer, they become agitated if they don't have a computer nearby and tend to give up real friendships in favor of online ones. In this way, the phenomenon of social isolation can be triggered, which is a major problem.

Starting from these considerations, we will focus on the number of real friends and on the evenings spent outside in their company.

Table 6. The number of close friends.

\begin{tabular}{cccc}
\hline Close friends & Neamt IT High School & Iasi IT High School & Total \\
\hline None & 8 & 10 & $18-9.78$ \\
One & 13 & 27 & $40-21.73 \%$ \\
Two & 37 & 25 & $62-33.69 \%$ \\
Three or more & 38 & 26 & $64-34.78 \%$ \\
\hline
\end{tabular}

The number of real friends may be higher or lower, but they must be present in the life of a teenager. We must consider the $9.78 \%$ of students who chose "none", a worrying result. On the other hand, there are $34.78 \%$ of students who have three or more friends, so they have a group of friends with whom they spend time in school and outside of it (Table 6).

The calculated differences are statistically significant $\mathrm{p}<0.05\left(f=3, \chi^{2}=9.438\right)$ and draw attention to the students from the high 
school in Neamt where the group of friends is much better represented.

The presence of friends indicates the existence of normal social relationships and time spent in their company. True friendship is not just about communicating online and during group games.

Unfortunately, the studied group has $19.56 \%$ of young people who choose the "none" option. They spend no time with friends, which is very concerning. On the other hand, we notice the presence of 5.43\% of young people who spend 6 to 7 days a week, with their friends, which is a little too much because they have a 6-hour school day, stay at the computer for at least 2-3 hours and outside for at least an hour. Then there is the question of the time available for studying and, especially, nighttime sleep. In most cases, young people spend 2-3 days per week outside with friends (38.04\%) or 1 day per week (28.80\%) (Table 7).

Table 7. Days spent outside with friends.

\begin{tabular}{cccccc}
\hline \multirow{2}{*}{ Group } & \multicolumn{5}{c}{ Days spent outside with friends } \\
\cline { 2 - 6 } & None & 1 day & $2-3$ days & $4-5$ days & 6 -7 days \\
\hline Neamt IT High School & 23 & 29 & 30 & 10 & 4 \\
Iasi IT High School & 13 & 24 & 40 & 5 & 6 \\
Total & 36 & 53 & 70 & 15 & 10 \\
$\%$ & 19.56 & 28.80 & 38.04 & 8.15 & 5.43 \\
\hline
\end{tabular}

Differences calculated are statistically insignificant ( $\left.>0.05, f=4, \chi^{2}=6.376\right)$ and show similar habits to be highlighted in terms of time spent in the presence of friends. This is an important aspect because during adolescence the tendency for isolation and loneliness can occur, especially for young people who spend a lot of time at the computer. In a Japanese adolescence study, $8.4 \%$ of young people favor loneliness and tend to isolate themselves socially (Endo, Ando, Shimodera, Yamasaki, Usami, Okazaki, Sasaki, Richards, Hatch \& Nishida, 2017). The percentage is similar to that obtained in our study; $9.78 \%$ young people have no true friends.

Such studies are important because they help to highlight adolescents that are at risk and offer the opportunity to intervene when needed.

It is necessary to continue the study on a larger group of pupils from different geographic regions of Romania. It would also be important to carry out a comparative study on pupils in several countries, which would allow for more comprehensive information. Future studies should start from a wider range of activities specific to leisure, which would allow a more accurate identification of the causes that favor the emergence of these problems. In view of these considerations, in the future, we intend to address the issues related to the time spent on physical activity or nighttime sleep. Physical activity is rarely present in the Romanian youth's daily program and sleep is considered by young people to be a waste of time. We will also focus on how parents interact with adolescents. Young people want to become independent, but they are not yet well prepared to achieve this goal. Parents have to be involved in the school activity and free time of the young person. Frequently, parents are very busy or do not know how to intervene, so many problems arise. There are families where these activities are considered to be solely the task of the school and the teachers, which is a big mistake.

\section{Conclusion}

The presence of school fatigue is confirmed by half of the students in the studied group. It is a phenomenon present in both high schools, which indicates intense school demands that exceed the students' effort capacity. Spending leisure time is a big problem because TV shows and computer activity can be demanding, increasing the fatigue that occurred during school hours. The presence of friends and the time spent outside, in their presence, is an element that highlights a normal social evolution. Unfortunately, there are also situations where young people do not have friends or do not spend free time with them, which is a big problem. 


\section{References}

Albu, A., Hodorcă, R. M., Onose, I., Negrea, M. \& Crăcană, I. (2016). The Evaluation of the Scholar Fatigue Phenomenon and Some Causative Factors in a Group of Teenagers from Lasi. Global Journal of Sociology, 6(2), 44-49. doi: https://doi.org/10.18844/gjs.v6i2.932

Albu, A. (2013). Evaluarea Fenomenului de Oboseală Scolară si a Unor Factori Care o Influentează la un lot de adolescenti de la liceul Dimitrie Cantemir din Iasi. Buletinul Academiei de Stiinte a Moldovei, 5(41), 63-68.

Alexander, R. (2010). Children, Their World, Their Education. London and New York: Routledge.

Buonomo, I., Cipriani, I., Piperno, S.,Saddi, I. \& Fiorilli, C. (2015). Internet and Socialization: How Internet Use Influences Online and Offline Relationships. Anthropological Researches and Studies, 5, 3-10.

Clerget, S. (2012). Criza Adolescentei. Bucuresti: Ed.Trei.

Cosmovici, A. \& Iacob, L. (2008). Psihologie Scolară. Iasi: Ed. Polirom.

Coyne-Beasley, T. (2017). Cultivating Connectedness and Equity: A Call to Action for the Global Adolescent Health Community. Journal of Adolescent Health, 61, 392-395. doi: http://dx.doi.org/10.1016/j.jadohealth.2017.07.001

Croitoru, C. (2015). Activitatea Copiilor la Computer si Cunostintele Copiilor si Părintilor Despre Activitatea la Computer, Functii si Disfunctii ale Familiei Contemporane, Rada C. \& Faludi C., Bucuresti: Ed. Universitară. doi: 10.5682/9786062801861

Eftodi, I., Mesina, V. \& Ferdohleb, A. (2013). Modificările Indicilor Psihofiziologici ai Oboselii la Studentii USMF "NICOLAE TESTIMITANU". Buletinul Academiei de Stiinte a Moldovei, 5(41), 36-40.

Endo, K., Ando, S., Shimodera, S., Yamasaki, S., Usami, S., Okazaki, Y., et al. (2017). Preference for Solitude, Social Isolation, Suicidal Ideation and Self-harm in Adolescents. Journal of Adolescent Health, 61, 187-191. doi: 10.1016/j.jadohealth.2017.02.018

Godeau, E., Arnaud, C. \& Navarro, F. (2008). La santé des élèves de 11 à 15 ans en France/2006, Paris: éditions inpes.

Rada, C. (2017). Impact of Some Demographic Parameters on Leisure Time and Body Weight. Anthropological Researches and Studies, 7 , 111-121. doi: http://doi.org/10.26758/7.1.12 